\title{
Sexual Exposure and Awareness of Emergency Contraceptive Pills among Never Married Adolescent Girls in India
}

\author{
Pralip Kumar Narzary \\ Fakir Mohan University Vyasa Vihar, Nuapadhi, India \\ pralipkn@gmail.com
}

\begin{abstract}
In India pre-marital sex although is taboo, interplay of multitude of factors exposes adolescent girls to pre-marital sex leading to unwanted pregnancy and further intricacies. Awareness of emergency contraceptive pills (ECP) can shield girls against such predicaments and associated social stigmas. Hence, this paper assesses the sexual exposure and awareness of ECP among the never married adolescent girls in India by taking the National Family Health Survey 2005-06 (NFHS-3) data. Out of the total sample, 15,320 adolescent girls of the age group 15-19 years, who are never married and de jure residents are retained for this study. Levels are found out through percentage distribution; associations are assessed through cross tabulation and logistic regression is applied to find out the determinants. It is found that in India, about 0.6 percent of never married adolescent girls have already experienced sex, out of whom 22.4 percent were active during four weeks prior to the survey. Multi-variate result shows that with the increase in age, probability of having pre-marital sex also increases, whereas with the improvement in household wealth index, probability goes down. Overall merely 4.9 percent of adolescent girls are aware of ECP. Age, education, religion and exposure to sexual intercourse exert significant effect on the awareness of ECP. Older, better educated, richer and sexually experienced girls are more likely to be aware of ECP, whereas rural and Muslim girls are less likely to be aware of ECP.
\end{abstract}

Key words: Pre-marital sex, unwanted pregnancy, emergency contraceptive pills, unmarried adolescent girls, emergency contraception

\section{Introduction}

Rapid modernization, westernization, lack of parental control, easy accessibility to mass media and pornographic materials, etc. expose adolescents to pre-marital sex. Further, behavioral factors that frequently put adolescents at greater risk of pre-marital sex include experimentation and risk taking attitude. Usually pre-marital sex, especially among adolescents is unplanned, thereby is unprotected. In India, pre-marital sex, especially for girls is taboo. Pre-marital sexual relationship is strongly discouraged and pre-marital pregnancy is socially highly stigmatized. Virginity is given high priority in marriage, so it is difficult to get a suitable match for sexually exposed unmarried girl. Unmarried pregnant girl and or having child is almost out of usual marriage market. However, studies show that pre-marital sex is not completely absent in India (Shashikumar et al., 2012; Ghule \& Donta, 2011; Sujay, 2009; Alexander et al., 2007; IIPS \& Macro International, 2007). Further, an extensive review of literature found that, in developing countries abortion and abortion related morbidity are most common among young unmarried women (Parker, 2005), which also implies that pre-marital sex among unmarried women in developing countries is not absent. By preventing unintended pregnancies, emergency contraception (EC) reduces the need for induced abortion and related complexities. Knowledge of EC would protect a large number of girls from the trauma of induced abortions, as well as reduce morbidities and mortalities and pregnancy complications (Sebastian et al., 2005). Available literatures suggest that EC is the term given to methods of contraception that can be used by women following unprotected vaginal sex to prevent an unplanned pregnancy. And, EC should be used within 120 hours of unprotected sex, preferably within 72 hours, although they are more effective the earlier they are taken.

Emergency Contraceptive Pills (ECP) contains higher doses of the hormones used in oral contraceptive pills. Existing studies (Trussell \& Raymond 2012; Hossain, 2009) show that there are three types of ECPs, namely [1] combined regimen of estrogen and progestin, [2] progestin-only ECPs, and [3] ECPs containing an 
antiprogestin (either mifepristone or ulipristal acetate). Dedicated progestin-only ECPs should be taken as a single dose of 1 tablet of $1.5 \mathrm{mg}$ or 2 tablets of $0.75 \mathrm{mg}$ each within 120 hours of unprotected intercourse. If a two-pill dose is used $(0.75 \mathrm{mg}$ each) these may be taken together or individually no more than 12 hours apart. Under the National Reproductive and Child Health Programme, the Drug Controller of India has approved only Levonorgestrel (LNG) $0.75 \mathrm{mg}$ tablets for use as ECP in India (MoHFW, 2008). Recognizing the merits associated with ECP, Government of India introduced it as a prescription drug in the national family planning program in 2003 (MoHFW, 2008) and since then efforts are also made to publicize ECP through mass media. Yet, available studies on ECP are basically conducted among service providers, small samples among the general mass and study among adolescents are almost untraceable. Further, studies addressing sexual exposure and EC in a single study are of utmost importance. Because, unprotected sexual intercourse leads to need of ECP and there is no denying the fact that adolescent pregnancy, marital or non-marital, in developing or developed country, poor or rich, educated or uneducated, is surrounded by complexities and intricacies. Further, by virtue of having second largest population in the world, India has very large adolescent population which makes study on adolescents much more relevant. Thus the aims of this paper are to know the levels and determinants of pre-marital sexual exposure of adolescent girls, linkage between pre-marital sex and awareness of ECP, and to know the levels and determinants of ECP in India.

\section{Literature Review}

Study on sexual behavior in Indian context is very limited, for which even the extensive reviewers had to admit that there is paucity of study (Joshi \& Chauhan, 2011). Similarly, study on ECP is also very rare. It may be mainly due to the sensitivity of the issue and unavailability of relevant data in public domain. Nevertheless, some noticeable issues can be extracted and inferred from available limited studies. Latest national family health survey 2005-06 report shows that in India 0.8 percent of never married women has had sexual intercourse (IIPS \& Macro International, 2007). Report also shows that 55 percent of the women who are currently 25-49 years old had first sexual intercourse before the age of 18 years, and 20 percent even before the age of 15 years. The median age at marriage for this group of women is only 16.8 years. This indicates that sexual exposure of adolescent girls in India is considerably high. Similarly, a study (Sujay, 2009) conducted among unmarried college youth in Gujarat shows that 27.2 percent of male and 4.3 percent female students had experienced sex at the age of 16 years or younger. A study (Shashikumar et al., 2012) conducted among co-education students of class IX to XII in Pune found that about 6.31 percent boys and 1.31 percent girls had experienced pre-marital sexual intercourse. Average age at first sexual intercourse was 15.25 years for boys and 16.66 years for girls. However, another study (Ghule \& Donta, 2011) conducted among rural college youth of Maharashtra shows slightly different picture. This study found that in Maharashtra, around 11 percent of boys and one percent of female students have experienced penetrative - oral/vaginal - pre-marital sex. Further, about 11 percent of boys and three percent of girls have reported having sex with same sex partner. Contrasting to these studies, a study (Sujay, 2009: 25) conducted in Gujarat shows that among the students who reported to have boy/girl friend, as high as 16.5 percent of female students and 30.4 percent of male college students reported to be engaging in sexual relations with an opposite sex partner.

Now it is very clear that different studies show different levels of sexual exposure among unmarried adolescent girls in India. But the existing studies are not comparable to each other due to differences in study design, or settings, or age group of sample, or marital status of respondents etc. Thus, it is complicated to really assess the level of pre-marital sexual intercourse among the never married adolescent girls with limited studies focused on these aspects. But, it can be well concluded that despite strong socio-cultural denunciation of pre-marital sexual relation, at least some girls venture out for pre-marital sexual relation. Study shows that age and exposure to pornographic films are significantly and positively associated with sexual experience among both male and female students; and among male students alcoholism is also found to be associated with pre-marital sexual relation (Sujay, 2009). Similarly, Ghule \& Donta (2011) also concludes that exposure to alcohol, drugs, pornographic films; having more frequent interaction with peers and working status of the students were positively related with penetrative and non-penetrative sexual relationship. A study on ECP (Puri et al., 2007) among female college students (of whom some are adolescents) in Chandigarh shows that even among the college students, only 7.3 percent had knowledge about ECP, among whom only 14.7 percent knew the correct time for its use. Unfortunately majority of the college going female students are either unaware or poorly informed of it. Similarly, even among tertiary level 
students in Trinidad only 63 percent of them have heard of emergency contraception (Parey et al., 2010). Studies (Kumar et al., 2007; Tripathi et al., 2003; Nayyar, 2000) show that in India, even the providers have poor knowledge about ECP and in general, women had little or no knowledge of ECP mainly regarding how to use it, or where to obtain it. However, they are keen to know about it (Kumar et al., 2007). Study conducted among Lady Health Supervisor in Pakistan also shows that most of the participants had inadequate knowledge of ECPs and have negative attitude towards it (Mir \& Malik, 2010). Similarly, Parker (2005) found that in general adolescents' access to and awareness of regular contraception is low, and awareness of and access to emergency contraceptive pills are even lower. Likewise, Narzary (2009) also found that even among the married adolescent girls, 12 percent does not have knowledge of any modern contraception in India. It means that pre-marital sex among adolescents is at greater risk, which may lead to unsafe abortion due to socio-cultural attitude attached to pre-marital sex and pregnancy.

Study shows that some women who do not have access to or have no knowledge of emergency contraception, resort to some traditional method of avoiding pregnancy (Kumar et al., 2007: 9), which may be ineffective and sometimes harmful as well. Other study (Puri et al., 2007) also shows that even college going female students are aware about only untested home remedies like jumping backward, blowing nose etc. More than half of tertiary level students in Trinidad felt that increased use of emergency contraceptive would enhance promiscuity, although 59 percent felt that emergency contraceptives should be made more easily available. Even though, the general level of their knowledge was poor but generally have positive attitude (Parey et al., 2010). But in Pakistan, emergency contraceptive providers and some women have negative attitude towards ECP (Mir \& Malik, 2010), similarly a few women in India expressed concern about misuse of ECP as a regular contraceptive, or by those engaging in pre-marital or extramarital sex (Kumar et al., 2007). However, if used rightly, ECP is an empowering tool allowing women to have more control over their reproductive lives (Jena, 2010) and avoid coercive pregnancy.

\section{Methodology}

The data for the present study comes from the National Family Health Survey 2005-2006 (NFHS-3).This is one of the nationwide surveys to have collected data on awareness and ever use of ECP in India. The sample in this survey was derived through multi-stage stratified sampling procedure (for details visit http://www.nfhsindia.org).The NFHS-3 included a nationally representative sample of 124,385 women aged 15-49 years, out of which 25,462 were never married. However, the analyses in this paper are based on the subsample of 15,320 never married adolescent girls 15-19 years, who are de jure resident and responded to the question on sexual exposure and ECP. In this paper, percentage distributions and mean are found out; associations are assessed through cross tabulation and logistic regression using SPSS 15 . The variable highest years of education contained 42 missing cases, which are excluded from the analysis. Further, variable ethnicity contained 554 missing cases, for which the variable itself is dropped from the multi-variate analysis. Because, missing cases relating to independent variables are automatically excluded from the entire analysis which reduces the sample size. Relating to the question of ECP, 13 girls did not respond, thereby the analyses of ECP are based on 15,307 unmarried adolescent girls, whereas analyses on sexual exposure are based on 15,320 samples. Further, some parts of the results may not add upto total or may be more than total due to the assigned sample weight. NFHS-3 collected information relating to sexual intercourse from all the women, irrespective of marital status. Before asking this question (investigators were instructed to) 'Check for the presence of others. Before continuing, make every effort to ensure privacy'. Further, investigators were instructed to assure privacy and confidentiality to respondents, and inform them about freedom of withdrawal from the interview at any time. Then, never married women were asked 'Have you ever had sexual intercourse?' Subsequently, along with questions on awareness and ever use of regular contraception, same question was also asked on ECP. Every respondent were asked 'Have you ever heard of EMERGENCY CONTRACEPTION Women can take pills up to three days after sexual intercourse to avoid becoming pregnant? If the women says 'yes', subsequently it's ever use was asked. Hence, it can be assumed that although asking question on sexual exposure and awareness of ECP among never married girls is very sensitive issue in country like India, responses are reliable and free from ethical dilemmas. Thus, if a girl replies in positive to question of 'sexual intercourse', then she is considered as sexually exposed. Similarly, if a girl replies in positive to question of ECP, then she is considered as aware of ECP. 


\section{Results and Discussion}

Sexual exposure and activeness: Uni-variate analysis (table: 1) shows that about 0.6 percent of never married adolescent girls in India have already experienced sex, out of them, 21.6 percent were active during four weeks prior to the survey. It implies that in terms of percentage, pretty negligible percentages are exposed to pre-marital sex, which should not be a matter of concern. But, if we look at the total number of adolescent girls, even 0.6 percent is very huge number for a country like India. Further, in current HIV/AIDS scenario and abortions, it is still a matter of quite serious concern. Thus, an attempt is made in the following sections to find out the determinants of pre-marital sex.

Table 1: Percentage distribution of respondents by sexual exposure and activeness

\begin{tabular}{lll}
\hline Status of sexual exposure and activeness & Frequency & Percent \\
\hline Sexually exposed & & \\
No & 15,223 & 99.4 \\
Yes & 97 & 0.6 \\
Total & 15,320 & 100.0 \\
Sexual activity in last four weeks & & \\
Active & 21 & 21.6 \\
Not active & 76 & 78.4 \\
Total & 97 & 100.0 \\
\hline
\end{tabular}

Determinants of pre-marital sex: Being somewhat traditional country, India's culture does not subscribe to pre-marital sex, but even then why do the adolescent girls venture out for it? To answer this question, initially bi-variate analysis is carried out followed by multi-variate analysis. Bi-variate analysis (table: 2) reveals that there is no distinct relationship between age of the respondent and the sexual exposure. But there is a negative relationship between education and the sexual exposure. As the education increases, the percentage of girls who are exposed to pre-marital sex reduces. This signifies that as girls become more educated they are comparatively free from forced sex, better aware of the negative effects and thereby remain away from pre-marital sex. This relationship however, may hold good only up to a certain level of education and thereafter the relationship may reverse. Because, as the level of education increases, they are likely to attend the new institution which is away from home, and may get more opportunity to mingle with opposite sex partner, which also opens the gateway for pre-marital sex.

Table 2: Percentage of adolescent girls by sexual exposure and background characteristics

\begin{tabular}{llll}
\hline Characteristics & $\begin{array}{l}\text { Sexually } \\
\text { Not exposed }\end{array}$ & Exposed & \\
\hline Age & & & \\
15 & 99.6 & 0.4 & 3876 \\
16 & 99.3 & 0.7 & 3888 \\
17 & 99.5 & 0.5 & 3146 \\
18 & 99.0 & 1.0 & 2746 \\
19 & 99.3 & 0.7 & 1665 \\
Highest year of education & & & \\
0 & 99.2 & 0.8 & 2355 \\
$1-4$ & 99.3 & 0.7 & 7596 \\
5 \& above & 99.5 & 0.5 & 5369 \\
Exposure to mass media & & & \\
Not exposed & 99.4 & 0.6 & 2204 \\
Partially exposed & 99.2 & 0.8 & 8547 \\
Highly exposed & 99.7 & 0.3 & 4548 \\
Place of residence & & & \\
Rural & 99.3 & 0.7 & 11198 \\
Urban & 99.6 & 0.4 & 4122 \\
Wealth index & & &
\end{tabular}




\begin{tabular}{llll} 
Poorest & 98.8 & 1.2 & 2504 \\
Poorer & 99.2 & 0.8 & 3029 \\
Middle & 99.4 & 0.6 & 3535 \\
Richer & 99.5 & 0.5 & 3419 \\
Richest & 99.9 & 0.1 & 2835 \\
Religion & & & \\
Hindu & 99.4 & 0.6 & 11927 \\
Muslim & 99.6 & 0.4 & 2458 \\
Others & 98.7 & 1.3 & 935 \\
Ethnicity & & & \\
Scheduled Caste & 98.9 & 1.1 & 2916 \\
Scheduled Tribe & 98.2 & 1.8 & 1322 \\
Other Backward Class & 99.5 & 0.5 & 6223 \\
None of the above & 99.8 & 0.2 & 4365 \\
Knowledge of modern contraception & & & \\
Don't know any method & 99.8 & 0.2 & 1231 \\
Knows some methods & 99.3 & 0.7 & 14089 \\
Aware about ECP & & & \\
Not aware & 99.4 & 0.6 & 14561 \\
Aware & 98.3 & 1.7 & 745 \\
Total & 15,223 & 97 & 15,320 \\
\hline
\end{tabular}

No distinct relationship between exposure to mass media and sexual exposure is observed. However, the percentage of adolescent girls exposed to pre-marital sexual relation is least among the girls who are highly exposed to mass media. This finding is in concurrence with the relationship between education and the premarital sexual exposure. Exposure to pre-marital sex is comparatively higher among the rural adolescent girls. This may be because forced sex is likely to be higher in the rural areas than the urban areas. Moreover, parents are comparatively more vigilant over their children in the urban areas. Further, due to the very natural set up and occupational structure, girls are likely to be more prone to coercive sex in the rural areas. While exploring the relationship between wealth status of the household and sexual exposure of the adolescent girls, a distinct negative relationship is observed. With the increase in wealth index, the percentage of sexually exposed adolescent girls decreases. This may imply that poor girls are more prone to forced sex, are compelled to have sex in turn of economic benefit etc. The percentage of the adolescent girls exposed to pre-marital sex is highest among the girls from other than Hindu or Muslim religion. This may be due to the stricter religious dogmas associated with Hindu and Muslim religions. Observation of result (table: 2) evidently shows that the percentage of sexually exposed girls is highest among the scheduled tribe, followed by the scheduled caste and other backward caste, whereas it is quite negligible among the general (forward) category. Due to the liberal culture (of some of the tribal groups), their pre-marital sexual exposure is much higher than other ethnic groups in the country. An attempt is made to know whether having knowledge of modern contraceptive method is linked with the pre-marital sex. It is observed that the girls having knowledge of contraception are more exposed than their counterpart. It implies that due to the necessity, the girls become aware of contraceptive methods. One step further, an attempt is also made here to find out the linkage between the awareness of ECP and sexual exposure. The linkage between exposure to pre-marital sex and EC however may be double edged. Adolescent girls having knowledge of ECP would have lesser fear of experimentation, whereas girls without its knowledge may not dare to shoulder such a mammoth risk. On the other hand, for sexually exposed adolescents, it becomes necessity to know about the EC. In this regard, result shows that there is significant difference in sexual exposure by awareness of ECP.

Girls who are aware of ECP are sexually more exposed than their counterpart. This may imply that girls who are exposed to pre-marital sex, due to very danger of getting pregnant, search for every possible solution. Under such circumstances, those girls become aware of ECP and also diffuse to peers in the process. Results of multi-variate analysis (table: 3) show that age, wealth index, exposure to mass media, awareness of ECP and religion are the significant factors affecting exposure to pre-marital sex among the adolescent girls in India. With every unit of increase in age, odds of sexual exposure increases significantly. Contrary to this, with the improvement in the wealth index, the odds of having pre-marital sex decreases quite significantly (odds 
ratio $0.619-0.096$ ), which means the necessity of indulging in pre-marital sex for direct or indirect economic gain significantly reduces for girls from economically better off households. And, this result is in the similar direction to the bi-variate result. Compared to the adolescent girls who are not exposed to mass media, partially exposed girls are more likely to have sexual exposure. Because of partial exposure to romantic and sexually appealing mass media, they may feel tempted to experiment sex, whereas fully exposed girls may become accustomed with such medias and may not get tempted. Thus, there is a need of censoring the contents of mass media by the government and monitoring of parents at the household level. Result also shows that compared to Hindu girls, respondents from other than Hindu and Muslim religions are more likely to have pre-marital sexual exposure. Strengthening the findings from bi-variate analysis, multi-variate analysis shows that girls who are aware of ECP are about four times more likely to be sexually exposed. Sexually exposed adolescents may look for all possible ways to prevent pregnancy, due to the stigma attached to pre-marital pregnancy. As a result become aware about ECP.

\section{Table 3: Results of Multi-variate analysis}

\begin{tabular}{|c|c|c|c|c|}
\hline \multirow[t]{2}{*}{ Independent Variable } & \multicolumn{4}{|c|}{$\begin{array}{l}\text { Dependant variable: sexually exposed? } \\
\text { Exposed }=1, \text { Not exposed }=0\end{array}$} \\
\hline & Categories & Beta & sig & Exp B \\
\hline Age of the respondent & (cont) & 0.174 & 0.024 & 1.190 \\
\hline Place of residence & $\operatorname{Urban}^{(\mathrm{R})}$ & & & \\
\hline \multirow[t]{2}{*}{ Highest year of education } & $\begin{array}{l}\text { Rural } \\
0^{(\mathrm{R})}\end{array}$ & 0.137 & 0.656 & 1.146 \\
\hline & $\begin{array}{l}1-4 \\
5 \& \text { above }\end{array}$ & $\begin{array}{l}-0.141 \\
-0.175\end{array}$ & $\begin{array}{l}0.629 \\
0.600\end{array}$ & $\begin{array}{l}0.868 \\
0.840\end{array}$ \\
\hline Exposure to mass media & $\begin{array}{l}\text { Not exposed }(\mathrm{R}) \\
\text { Partially exposed } \\
\text { Highly exposed }\end{array}$ & $\begin{array}{l}0.660 \\
0.025\end{array}$ & $\begin{array}{l}0.042 \\
0.953\end{array}$ & $\begin{array}{l}1.934 \\
1.026\end{array}$ \\
\hline \multirow[t]{2}{*}{ Religion } & Hindu $^{(R)}$ & & & \\
\hline & Muslim & $\begin{array}{l}-0.376 \\
0.915\end{array}$ & $\begin{array}{l}0.264 \\
0.004\end{array}$ & $\begin{array}{l}0.687 \\
2496\end{array}$ \\
\hline \multirow[t]{5}{*}{ Wealth index } & Poorest $(\mathrm{R})$ & & & \\
\hline & Poorer & -0.480 & 0.086 & 0.619 \\
\hline & Middle & -0.785 & 0.009 & 0.456 \\
\hline & Richer & -1.018 & 0.003 & 0.361 \\
\hline & Richest & -2.339 & 0.000 & 0.096 \\
\hline \multirow[t]{2}{*}{ Awareness of ECP } & Not aware $(\mathrm{R})$ & & & \\
\hline & Aware & 1.429 & 0.000 & 4.174 \\
\hline
\end{tabular}

Note: $\left.{ }^{\mathrm{R}}\right)=$ Reference category; ${ }^{(\mathrm{cont})}=$ Continuous variable

Linkage between awareness of ECP and pre-marital sex: An attempt is made here to assess the linkage between the awareness of ECP and pre-marital sexual experience. The result (table: 4) shows that overall five percent of the unmarried adolescent girls in India are aware of the ECP, whereas remaining 95 percent are not aware of it and the result is statistically highly significant. It means that quite negligible percentages of adolescent girls are aware of it, which directly calls for immediate attention of policy makers. It is also quite apparent that among the girls who are exposed to pre-marital sex, as high as 13 percent are aware of ECP. This result implies that the girls who are sexually exposed might have looked for all possible means to avoid pregnancy, and might have become aware of ECP. Whereas, one can also argue that the girls who are aware of ECP dare to experience pre-marital sex. But in this study former adage is assumed. One step further, the awareness of ECP is assessed by the sexual activeness in last four weeks preceding the survey. Result (table: 4) shows that the awareness of ECP is strikingly higher (19\%) among the girls who are sexually active in last four weeks, compared to the girls who are not active $(11.8 \%)$ in the reference period. This further strengthens the assumption that due to the compelling circumstances adolescent girls become aware of ECP. Thus, there is a very strong need to make adolescent girls not only aware, but also knowledgeable about the ECP and other EC methods. 
Table 4: Percentage of adolescent girls by sexual exposure and activeness, and awareness of ECP

\begin{tabular}{llll}
\hline & \multicolumn{3}{l}{ Awareness of ECP } \\
Sexual status & Not aware & Aware & n \\
\hline Not exposed & 95.2 & 4.8 & 15,209 \\
Sexually exposed & 86.6 & 13.4 & 97 \\
Total & 95.1 & 4.9 & 15,307 \\
$\chi^{2}: 15.356 ; \mathrm{p}=0.00$ & & & \\
Active & 81.0 & 19.0 & 21 \\
Not active & 88.2 & 11.8 & 76 \\
Total & 86.5 & 13.5 & 97 \\
$\chi^{2}: 0.296 ; \mathrm{p}=0.58$ & & & \\
\hline
\end{tabular}

Awareness of ECP: Result (table: 5) shows that there is a linkage between age and awareness of ECP. As the age increases, percentage of girls having awareness of ECP increases. Similarly, with the increase in years of education percentage of girls having awareness of ECP also increases. It means that there is a great need to provide information of ECP to girl children at younger ages.

Table 5: Percentage of unmarried adolescent girls by awareness of ECP

\begin{tabular}{|c|c|c|c|}
\hline Characteristics & Not aware & Aware & Cases \\
\hline \multicolumn{4}{|l|}{ Age } \\
\hline 15 & 96.7 & 3.3 & 3874 \\
\hline 16 & 95.9 & 4.1 & 3885 \\
\hline 17 & 94.8 & 5.2 & 3145 \\
\hline 18 & 94.8 & 5.2 & 2745 \\
\hline 19 & 91.0 & 9.0 & 1655 \\
\hline \multicolumn{4}{|c|}{ Highest year of education } \\
\hline 0 & 98.9 & 1.1 & 2355 \\
\hline $1-4$ & 95.1 & 4.9 & 7590 \\
\hline $5 \&$ above & 93.5 & 6.5 & 5363 \\
\hline \multicolumn{4}{|l|}{ Exposure to mass media } \\
\hline Not exposed & 98.0 & 2.0 & 2204 \\
\hline Partially exposed & 95.9 & 4.1 & 8541 \\
\hline Highly exposed & 92.3 & 7.7 & 4541 \\
\hline \multicolumn{4}{|l|}{ Place of residence } \\
\hline Rural & 95.9 & 4.1 & 11190 \\
\hline Urban & 93.1 & 6.9 & 4117 \\
\hline \multicolumn{4}{|l|}{ Wealth index } \\
\hline Poorest & 97.4 & 2.6 & 2503 \\
\hline Poorer & 97.0 & 3.0 & 3025 \\
\hline Middle & 96.2 & 3.8 & 3533 \\
\hline Richer & 93.8 & 6.2 & 3418 \\
\hline Richest & 91.5 & 8.5 & 2827 \\
\hline \multicolumn{4}{|l|}{ Religion } \\
\hline Hindu & 94.8 & 5.2 & 11917 \\
\hline Muslim & 96.4 & 3.6 & 2457 \\
\hline Others & 95.5 & 4.5 & 932 \\
\hline \multicolumn{4}{|l|}{ Ethnicity } \\
\hline Scheduled Caste & 95.8 & 4.2 & 2912 \\
\hline Scheduled Tribe & 95.8 & 4.2 & 1322 \\
\hline Other Backward Class & 95.0 & 5.0 & 6219 \\
\hline None of the above & 94.6 & 5.4 & 4362 \\
\hline \multicolumn{4}{|c|}{ Exposed to pre-marital sex } \\
\hline No & 95.2 & 4.8 & 15209 \\
\hline Yes & 86.6 & 13.4 & 97 \\
\hline Total & 95.1 & 4.9 & 15,307 \\
\hline
\end{tabular}


Result (table: 5) reveals that the exposure to mass media is also another crucial variable that plays role in making adolescent girls aware of ECP. Among girls who are not at all exposed to any mass media, only two percent, among partially exposed about four percent, whereas among the girls who are fully exposed as high as eight percent are aware of ECP. Mass media, especially TV, is one of the best means of creating awareness about any issue. It is also easy for individuals to understand the issue from audio-visual mass media. Compared to rural girls, much higher percentage of girls from urban areas are aware of ECP. This may be due to availability of better information, education and communication (IEC) system in the urban areas. It is found that there is a distinct positive relationship between the wealth index of the household and the awareness of ECP. The percentage of adolescent girls who are aware of ECP also increases as the wealth index improves. This may be due to the fact that with the improvement in wealth status, household possesses various means of mass media, through which adolescents become aware of ECP. A glance in the table also reveals that awareness of ECP is comparatively lesser among Muslim girls, than girls from Hindu and other religion. Relationship between ethnicity and awareness of ECP exhibits a very well established hierarchy. The awareness of ECP is poorer among scheduled caste/tribe girls than that of other backward caste and advance caste girls. This may be the result of socio-economic status associated with ethnic groups. Further, an attempt is made to assess the relationship between exposure to pre-marital sex and awareness of ECP, by controlling the effect of some other variables like age, place of residence, education, exposure to mass media, religion and wealth index And, this result (table: 6) depicts a distinct picture that awareness of ECP is much higher among the sexually exposed girls, if we control the effect of other variables. Result also shows that with the increase in age of the adolescent girls, the odds of having awareness of ECP also increases. This implies that as the adolescents grow older, they become more aware of ECP.

This finding is in similar direction to the bi-variate result. Another very significant determinant of awareness of ECP is the years of education. Compared to girls who have never been to school, the odds of knowing ECP increases with the years of education (odds ratio 3.231 - 3.399). Further, result indicates that compared to girls who have never been to school, girls with 1-4 years of education and 'five years and above' education are much more likely to be aware of ECP. It means that the years of education have a great contribution in the awareness of ECP. Mention may be made here that EC is not a part of school or college curriculum in India, but as the education increases girls can lay their hands on various written or audio visual materials that talks about ECP and become aware. Another significant finding is that 'sexually exposed' girls are much more likely (odds ratio 4.032) to be aware of ECP. This result further strengthens the findings of bi-variate analysis. The relationship between exposure to mass media and awareness of ECP is not very clear (table: 6). It is found that there is no significant difference between 'not exposed' and 'partially exposed' girls. But compared to 'not exposed' girls, 'highly exposed' girls are much more likely to be aware of ECP (odds ratio 1.675). If a girl is exposed to all the three means of mass media (news paper, radio and TV), it will be sure that she will come across advertisement of ECP from one or the other medias. This implies that message of ECP coverage is not yet widespread in India, which calls for its enhancement. Compared to Hindu girls, Muslim and girls from 'others' religion are less likely to be aware of ECP (odds ratio $0.782-0.702$ ). This may be partially due to the fact that Muslim girls in India are comparatively less educated and partially due to stricter religious doctrine.

Table: 6 Result of Multi-variate analysis

\begin{tabular}{|c|c|c|c|c|}
\hline \multirow[t]{2}{*}{ Independent variables } & \multicolumn{4}{|c|}{$\begin{array}{l}\text { Dependant variable: Aware of ECP? } \\
\text { Aware }=1 \text {, Not aware }=0\end{array}$} \\
\hline & Categories & Beta & Sig & Exp B \\
\hline Age of the respondent & (cont) & 0.181 & 0.000 & 1.198 \\
\hline Place of residence & $\begin{array}{l}\text { Urban }^{(\mathrm{R})} \\
\text { Rural }\end{array}$ & -0.150 & 0.092 & 0.860 \\
\hline Highest year of education & $\begin{array}{l}0^{(\mathrm{R})} \\
1-4 \\
5 \text { \& above }\end{array}$ & $\begin{array}{l}1.173 \\
1.223\end{array}$ & $\begin{array}{l}0.000 \\
0.000\end{array}$ & $\begin{array}{l}3.231 \\
3.399\end{array}$ \\
\hline
\end{tabular}




\begin{tabular}{|c|c|c|c|c|}
\hline Exposure to mass media & $\begin{array}{l}\text { Not exposed(R) } \\
\text { Partially exposed } \\
\text { Highly exposed }\end{array}$ & $\begin{array}{l}0.128 \\
0.516\end{array}$ & $\begin{array}{l}0.460 \\
0.005\end{array}$ & $\begin{array}{l}1.137 \\
1.675\end{array}$ \\
\hline Religion & $\begin{array}{l}\operatorname{Hindu}^{(\mathrm{R})} \\
\text { Muslim } \\
\text { Others }\end{array}$ & $\begin{array}{l}-0.246 \\
-0.354\end{array}$ & $\begin{array}{l}0.038 \\
0.033\end{array}$ & $\begin{array}{l}0.782 \\
0.702\end{array}$ \\
\hline Wealth index & $\begin{array}{l}\text { Poorest(R) } \\
\text { Poorer } \\
\text { Middle } \\
\text { Richer } \\
\text { Richest }\end{array}$ & $\begin{array}{l}-0.088 \\
-0.009 \\
0.324 \\
0.513\end{array}$ & $\begin{array}{l}0.598 \\
0.956 \\
0.042 \\
0.002\end{array}$ & $\begin{array}{l}0.915 \\
0.991 \\
1.383 \\
1.670\end{array}$ \\
\hline Exposed to pre-marital sex & $\begin{array}{l}\mathrm{No}^{(\mathrm{R})} \\
\text { Yes }\end{array}$ & 1.394 & 0.000 & 4.032 \\
\hline
\end{tabular}

Note: $(\mathrm{R})=$ Reference category; $($ cont $)$ = Continuous

The linkage between wealth index of the household and girls' awareness of ECP shows that the girls from last two quintiles (richer and richest) household are more likely to be aware, whereas girls from poorer and middle income family do not show any significant relationship. This implies that to make girls aware of ECP, certain level of economic condition is also necessary. The multi-variate result (table: 6) confirms that there is a strong relationship between exposure to pre-marital sex and awareness of ECP. The girls who are sexually exposed are 1.39 times more likely to be aware of ECP than those who are not exposed. Making adolescents aware of ECP is necessary not only to save them from social stigma of pre-marital pregnancy, but also to protect them from unplanned conjugal pregnancy in their future course of life.

\section{Conclusion}

Existing literatures on pre-marital sex and ECP in Indian context are very inadequate. Available studies are mainly based on small area and sample. Studies are also not uniform in terms of age of the respondents, some dealt with never married adolescents, whereas others dealt with unmarried youth, while some others dealt with both married and unmarried adolescents and or youth etc. Hence, it is very difficult to come to a commendable conclusion on levels and determinants of both pre-marital sexual exposure and awareness of ECP. But as the present study is based on nationwide sample, restricted to never married adolescent girls and restricted age group of 15-19 years, it may be very useful for future researchers for reference. Further, the changes in the society are unavoidable and complete restrictions on pornographic materials may not be possible. Also, the situations which are pushing adolescent girls to pre-marital sex are complex and mostly beyond control. Nevertheless, spreading the awareness and knowledge of ECP is one of the most suitable ways to safeguard girls against unwanted pre-marital pregnancy and social stigma associated with it. Thus, there is an urgent need to make adolescents aware and knowledgeable about ECP, so that they can be cosseted from anticipated lifelong encumbers.

Recommendation: From the extensive review of literature and present study, it is felt that nationwide large scale surveys with the prime objective of studying issues concerning EC are required. Such surveys among unmarried adolescents are of utmost importance. Studies among un/married youth and adults are nevertheless of no less importance. Appropriate plans can be made based on findings of such studies. If the course curriculum of formal education cannot be over loaded with additional chapter on contraceptive methods, especially EC, at least occasional lecture series may be ear-marked for imparting knowledge on this issue. Further, as India is predominantly rural and there are evidences of pre-marital sexual exposure among rural adolescent girls as well, steps should be taken to make them aware of ECP. Such steps should be just added in to the ongoing appropriate program. Integrated child health development services (ICDS) workers and accredited social health activists (ASHA) may be imparted with knowledge of EC and entrusted to make adolescents as well as pregnant mothers aware of EC. Documentary films encompassing details of EC and negative consequences of unwanted pregnancy may be prepared by taking very popular film actors and 
actress and same may be telecast through television. Further, in the areas where the family life education is already a part of school curriculum, EC also may just be added as another chapter. Initiating completely a new program in the name of EC is not recommended, because India is a very vast country, where running a new program needs enormous resources.

\section{References}

Alexander, M., Garda, L., Kanade, S., Jejeebhoy, S. \& Ganatra, B. (2007). Correlates of premarital relationships among unmarried youth in Pune District, Maharashtra, India. International Family Planning Perspective, 33(4), 150-159.

Ghule, M. \& Donta, B. (2011). Correlates of sexual behavior of rural college youth in Maharashtra, India. Eastern Journal of Medicine, 16, 122-132.

Hossain, S. M. I. (2009). ECP handbook: Introducing and mainstreaming the provision of emergency contraceptive pills in developing countries, FRONTIERS Manual. Washington, DC: Population Council.

International Institute for Population Sciences (IIPS) \& Macro International (2007). National family health survey (NFHS-3), 2005-06: India: Volume I. Mumbai: IIPS.

Jena, M. (2010). Rising Use of Emergency Contraceptives Raises Alarm. http://ipsnews.net/news.asp?idnews=51529 (accessed 07/09/2011).

Joshi, B. \& Chauhan, S. (2011). Determinants of youth sexual behavior: program implications for India. Eastern Journal of Medicine, 16, 113-121.

Kumar, S., Shekhar, C., Gupta, N. K. \& Roy, M. (2007). Provision of Emergency Contraceptive Services through Paraprofessionals in India. Indian Council of Medical Research (ICMR), Frontiers in Reproductive Health (FRONTIERS), Population Council, and Human Reproduction Research Centers (HRRCs), ICMR.

Mir, A. S. \& Malik, R. (2010). Emergency contraceptive pills: Exploring the knowledge and attitudes of community health workers in a developing Muslim country. North A J Med Sci, 2, 359-364.

Ministry of Health \& Family Welfare. (2008). Guidelines for administration of Emergency Contraceptive Pills by Health Care Providers. MoHFW, Govt. of India, New Delhi.

Narzary, P. K. (2009). Knowledge and use of contraception among currently married adolescent women in India. Stud Home Comm Sci, 3(1), 43-49.

Nayyar, A. (2000). Increasing access to emergency contraception in India, Health and Population, Perspectives and Issues, 23(3), 123-133.

Parey, B., Addison L., Mark, J. K., Maurice, B., Tripathi, V., Wahid, S., Antoine, R. \& Sahai, A. (2010). Knowledge, attitude and practice of emergency contraceptive pills among tertiary level students in Trinidad: a cross sectional survey. West Indian Med. J., 59(6), 650-55.

Parker, C. (2005). Adolescents and emergency contraceptive pills in developing countries. Working Paper No. WP05-01, Family Health International.

Puri, S., Bhatia, V., Swami, H. M., Singh, A., Sehgal, A. \& Kaur, A. P. (2007). Awareness of emergency contraception among female College students in Chandigarh, India. Indian J Med Sci., 61(6), 338-346.

Sebastian, M. P., Khan, M. E., Kumar, S., Shekhar, C. \& Gputa, N. K. (2005). Studying the use of emergency contraceptive services through paramedics in India. Research Update No. 5, September 2005. New Delhi: Population Council/FRONTIERS.

Shashikumar, R., Das, R. C., Prabhu, H. R. A., Srivastava, K., Bhat, P. S., Prakash, J. \& Seema, P. (2012). A cross sectional study of factors associated with adolescent sexual activity. Indian Journal of Psychiatry, 54 (2), 138-143.

Sujay, R. (2009). Premarital sexual behavior among unmarried college students of Gujarat, India. Health and Population Innovation Fellowship Program Working Paper, No. 9. New Delhi: Population Council.

Tripathi, R., Rathore, A. M. \& Sachdeva, J. (2003). Emergency contraception: knowledge, attitude, and practices among health care providers in North India. J Obstet Gynaecol Res, 29(3), 142-46.

Trussell, J. \& Raymond, E. G. (2012). Emergency Contraception: A last chance to prevent unintended pregnancy. (Accessed 11/09/2012, http: //ec.princeton.edu/questions/ec-review.pdf). 